\title{
Performance evaluation of a battery-cooling system using phase-change materials and heat pipes for electric vehicles under the short-circuited battery condition
}

\author{
Hirotaka HATA*, Shumpei WADA*, Tatsuya YAMADA*, Koichi HIRATA**, Takashi YAMADA* and \\ Naoki ONO* \\ ${ }^{*}$ Department of Engineering Science and Mechanics, Shibaura Institute of Technology \\ 3-7-5, Toyosu, Koto-ku, Tokyo, 135-8548, Japan \\ E-mail: naokiono@sic.shibaura-it.ac.jp \\ **Power and Energy System R\&D Center, Marine Environment \& Engine System Department, National Maritime Research Institute \\ 6-38-1, Shinkawa, Mitaka-shi, Tokyo, 181-0004, Japan
}

Received: 31 May 2018; Revised: 8 July 2018; Accepted: 12 July 2018

\begin{abstract}
Electrical vehicles equipped with lithium-ion batteries (LiBs) have been increasing in popularity on the market. LiBs have high energy density and high electric current; however, their lifetimes and performance are known to be strongly influenced by temperature rise due to heat generation, and thermal runaway may occur when the battery temperature exceeds $80{ }^{\circ} \mathrm{C}$. Hence, the development of LiB thermal-management technology is essential. In this study, an A4-sized LiB was short circuited in a prototype cooling system with phase-change material (PCM) and heat pipes (HPs), and the performance of the cooling system was evaluated. To compare the cooling performances, four experimental conditions were adopted: a combination of PCM and HP; PCM only; HP only; and not using the cooling system. In addition, a simulation was conducted under the experimental conditions using a scale model of the cooling system. Thus, we confirmed that the temperature increase of the $\mathrm{LiB}$, especially up to $80^{\circ} \mathrm{C}$, was extended by the effects of PCM. The combination of PCM and $\mathrm{HP}$ suppressed the temperature of $\mathrm{LiB}$ to be about $80^{\circ} \mathrm{C}$.
\end{abstract}

Keywords: Lithium-ion battery, Abnormal heat generation, Short circuit, Thermal management technology, Phase change material, Heat pipes

\section{Introduction}

In recent years, the emissions of greenhouse gases and air pollutants that accompany economic development have become major problems. Economies dependent on fossil fuels for their energy needs in particular are facing serious issues (Poizot and Dolhem, 2011; Hamut et al., 2012). Therefore, it is urgent to develop new energy sources to replace fossil fuels, especially highly efficient renewable energy (Scrosati and Garche, 2010). Recently, electric vehicles (EVs), hybrid electric vehicles, and plug-in hybrid electric vehicles have increased in popularity (Tie and Tan, 2013). Lithium-ion batteries (LiB) are used in these EVs; LiB have high energy density, high power density, and are environmentally friendly; they are widely used as clean-energy sources (Saito, et al. 1997 and Qian, et al. 2016). The International Energy Agency (IEA) reported in 2016 that the number of EVs in the world has reached 2 million. The IEA also predicts that this number will increase rapidly (IEA ed., 2017). However, it is said that the lifetime and performance of LiB are strongly influenced by temperature rise due to heat generation caused by charge, discharge, and the like(Ramadass et al., 2002a, 2002b; Wang et al., 2016; Yuksel et al., 2016). In addition, thermal runaway is caused when the temperature of a LiB exceeds around $80^{\circ} \mathrm{C}$ due to short circuiting (Hammami et al., 2003). Gas release, firing, and explosions sometimes accompany such thermal runaway (Lisbona and Snee, 2011; Wang et al., 2012; Pesaran et al., 2013). Therefore, improvement of LiB thermal-management technology is necessary. 
Many studies on thermal-management technologies for LiB, such as air- and water-cooling methods, have been performed (Zhang et al., 2009; Fan et al., 2013; Mohammadian and Zhang, 2015). Cooling methods using phase-change materials have also been investigated (Al-Hallaj and Selman, 2000; Khateeb et al., 2005; Javani et al., 2014). Recently, a cooling system combining phase-change materials and mini channels has been developed. Rao et al. designed such a combination system and investigated the influence of fluid-flow rate in the mini channel and thermal conductivity of the phase-change material upon the LiB temperature by simulation. An optimal value of the fluid-flow rate was calculated from this study. Moreover, it was confirmed that the temperature of the LiB can be lowered by increasing the thermal conductivity of the phase-change material (Rao et al., 2016). Xu et al. developed a mini-channel cooling system at batterymodule level and numerically simulated it with a nail-penetration model. It was found that the propagation of thermal runaway from one LiB to the adjacent one can be prevented by a mini-channel cooling system capable of independently controlling the coolant-flow rate for each LiB (Xu et al., 2017).

In spite of these studies, fire accidents in LiB-powered EVs and aircraft due to LiB breakdown or accidents have been reported in the past 10 years (Feng et al., 2017). Many of these fire accidents are thought to have occurred as a result of short circuiting and thermal runaway of the LiB. In addition, if any accidents occur and the power necessary for cooling by water or forced air cannot be obtained, a sufficient cooling effect may not be secured. We believe that it is necessary to establish a technology that can cool LiB even in such severe cases.

The authors have previously developed a prototype hybrid-type cooling system using heat pipes (HP) and phasechange material (PCM), and examined the cooling performance of this system (Yamada et al. al., 2017). In this study, one $\mathrm{LiB}$ incorporated into the cooling system was actually short-circuited and its cooling performance was verified. In order to compare the cooling performance, experiments were conducted under four experimental conditions: cooling using a combination of PCM and HP, cooling using PCM only, cooling using HP only, and without using cooling system. Moreover, heat-transfer calculations were performed under experimental conditions using the same scale model as the cooling system and the system's thermal behavior was analyzed by comparing both results.

\section{Experimental device and method}

\subsection{Preliminary experiment}

In evaluating the performance of this cooling system, it was necessary to determine how long the temperature rise of the LiB should be suppressed. For this reason, a preliminary experiment in which a single LiB cell was externally shortcircuited was conducted. The external short circuit was made in a thermostatic chamber with a single LiB connected to the magnetic contactor via conducting wires. The magnetic contactor was made by Fuji Electric FA Components \& Systems Co., Ltd. (SB-N2 type), and the conducting wires were made by Mitsuboshi Co., Ltd. (2PNCT type, cross section: $60 \mathrm{~mm}^{2}$ ). The time of the external short circuit could be arbitrarily set by opening and closing the switch inside the magnetic contactor. For the preliminary experiment, a laminate-type LiB (size: $237 \mathrm{~mm} \times 201 \mathrm{~mm} \times 8.5 \mathrm{~mm}$, nominal capacity: $22 \mathrm{Ah}$, cathode: lithium iron phosphate $\left(\mathrm{LiFePO}_{4}\right)$, anode: graphite) was used. A schematic view of preliminary experiment is shown in Fig. 1. The temperature-measurement positions of LiB were set on the surface near the anode and near the center, respectively. The LiB-temperature results shown in this paper are the highest values of these two positions. K-type sheath thermocouples were used for temperature measurement and GRAPHTEC GL820 was used as a data logger. Temperature changes were recorded at 0.1 second intervals. A program-logic controller (PLC) was used to control the switch opening / closing of the magnetic contactor.

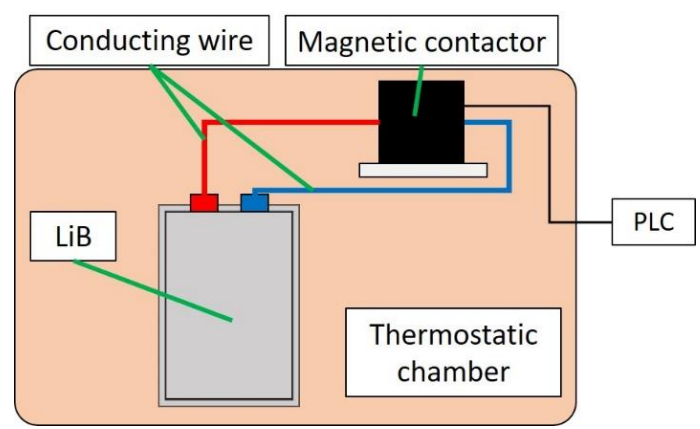

Fig. 1 Schematic view of the preliminary experiment in the thermostatic chamber. 
Changes in the temperature and heat generation of the LiB in the preliminary experiment are shown in Fig. 2 . The $\mathrm{LiB}$ temperature sharply increased immediately after the start of the short circuit and reached $80{ }^{\circ} \mathrm{C}$ within about 20 seconds. Although temperature temporarily decreased afterward, the maximum temperature reached $116.7^{\circ} \mathrm{C}$ after 186 seconds. Despite the LiB temperature decreasing slowly after reaching its maximum, heat generation had already decreased greatly when the maximum temperature was reached. Heat generation was calculated using Eq. (1) based on the temporal change of the battery temperature obtained in the experiment,

$$
Q=m c \Delta T
$$

Here, $Q[\mathrm{~W}]$ is the heat-generation of the battery, $m[\mathrm{~kg}]$ is the battery mass, $c[\mathrm{~J} /(\mathrm{kg} \cdot \mathrm{K})]$ is the specific heat of the battery, and $\Delta T\left[{ }^{\circ} \mathrm{C} / \mathrm{s}\right]$ is the temperature difference per unit time. From this result, the initial peak of heat generation itself was considered to have little influence upon thermal runaway of the LiB after a certain time passed. Therefore, it was important to determine how LiB-temperature rise can be suppressed up to 200 seconds after short circuiting commences. Accordingly, for subsequent experiments and simulations, the results up to 200 seconds after the start of short circuiting were investigated. In this preliminary experiment, there was no constraint on the shape of the LiB cell, and the LiB was short-circuited after putting it on a plate. Therefore, about 40 seconds after starting LiB short circuiting (when LiB temperature reached about $90{ }^{\circ} \mathrm{C}$ ), expansion of the LiB started and its thickness finally reached 5 to 6 times the initial value. This result is shown in Fig. 3.

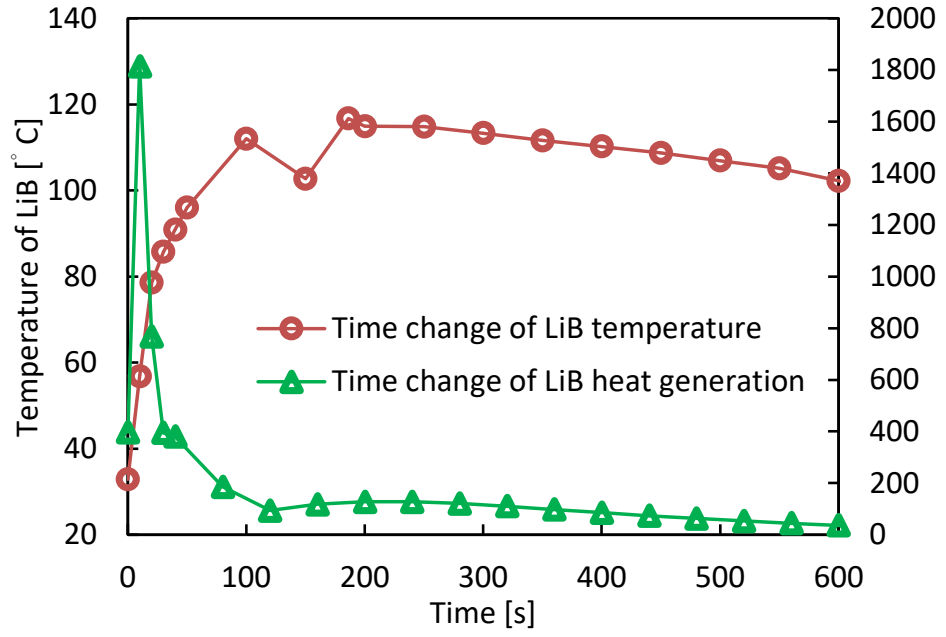

Fig. 2 Change of LiB temperature and heat generation in the preliminary experiment.

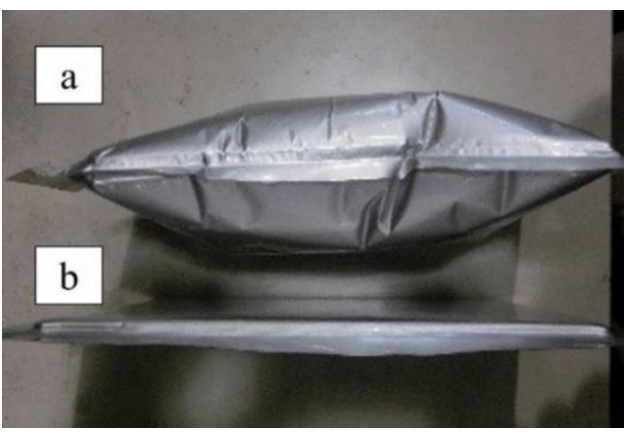

Fig. 3 Expansion of the LiB (a) After preliminary experiment, (b) Before the preliminary experiment.

\subsection{The cooling system}

From the preliminary experimental results, the temperature of the LiB was found to peak about 200 seconds after short circuiting started and the cooling performance up to this time was very important. Therefore, in this study, using the hybrid cooling system with PCM and HP devised by Yamada et al., the cooling performance to that time was mainly investigated. For this cooling system, the cooling performance at a heat generation of $400 \mathrm{~W}$ was reported (Yamada et al., 2017). This cooling system is shown in Fig. 4; the cooling system was constituted for a battery module in which four LiB were arranged in parallel (Fig.4 (b)). Twenty HPs were installed on each side of the battery module so that forty HPs were in contact with the LiB. HP had ten fins at a $7.5 \mathrm{~mm}$ interval on each side, twenty fins in total. PCM filled the gap between the LiB, HP, and container. The heat flow of this cooling system is shown schematically in Fig. 5. Heat generated from the LiB was transported to the PCM and HP, respectively. Part of the heat transferred to the PCM was stored as latent heat and the other heat moved to the HP and then was released to the outside air through the fins.

LiB cells, which were the same as in the preliminary experiment, were loaded into the system. HP was made of copper (flat part: $120 \mathrm{~mm} \times 10 \mathrm{~mm} \times 3 \mathrm{~mm}$, cylindrical part: $100 \mathrm{~mm} \times \varphi 8 \mathrm{~mm}$ ) and the working fluid in HP was pure water (Fig.4 (c)). The basic shape of HP used in the cooling system was cylindrical shape with diameter of $8 \mathrm{~mm}$, which was later compressed to have flat portion of $3 \mathrm{~mm}$ thickness. The fin was made of aluminum (size: $230 \mathrm{~mm} \times 119 \mathrm{~mm} \times$ 
$0.3 \mathrm{~mm}$ ), the container was made of polyvinyl chloride (size: $200 \mathrm{~mm} \times 49 \mathrm{~mm} \times 220 \mathrm{~mm}$ ). RT50 (melting point: 45 to $51{ }^{\circ} \mathrm{C}$, thermal conductivity: $0.2 \mathrm{~W} /(\mathrm{m} \cdot \mathrm{K})$ ) made by Rubitherm Technologies $\mathrm{GmbH}$ (company of Germany) was used as a PCM. Thermal runaway occurs at LiB internal temperatures above about $80{ }^{\circ} \mathrm{C}$; therefore, it is necessary to suppress the temperature of the $\mathrm{LiB}$ below $80^{\circ} \mathrm{C}$ within 200 seconds after short circuiting commences. To effectively suppress $\mathrm{LiB}$ temperature using the latent heat of PCM, RT50 with a melting point below the actual thermal-management-target temperature of $50^{\circ} \mathrm{C}$ was selected.

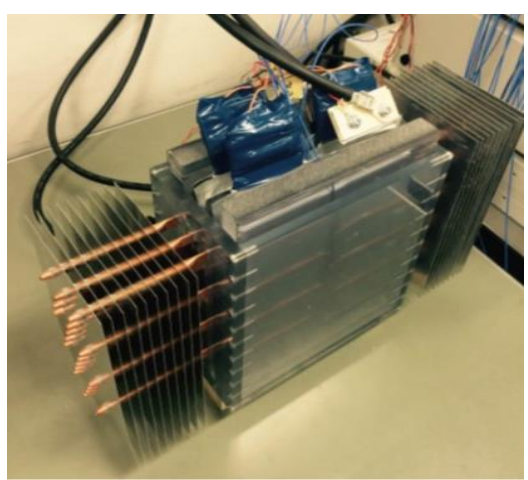

(a)

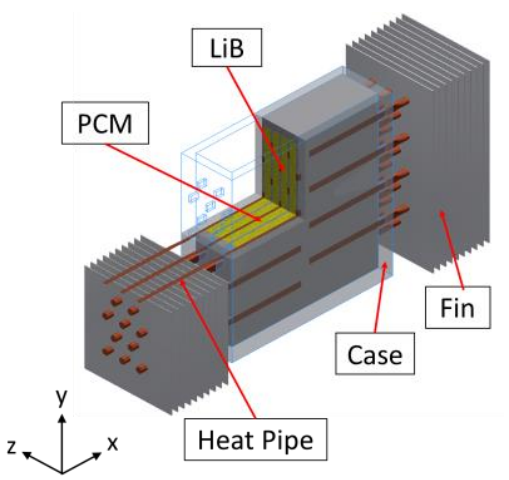

(b)

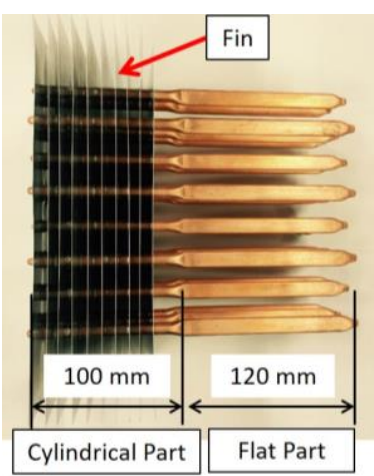

(c)

Fig. 4 The cooling system (a) Over view, (b) Schematic view, (c) Heat pipes with fins.

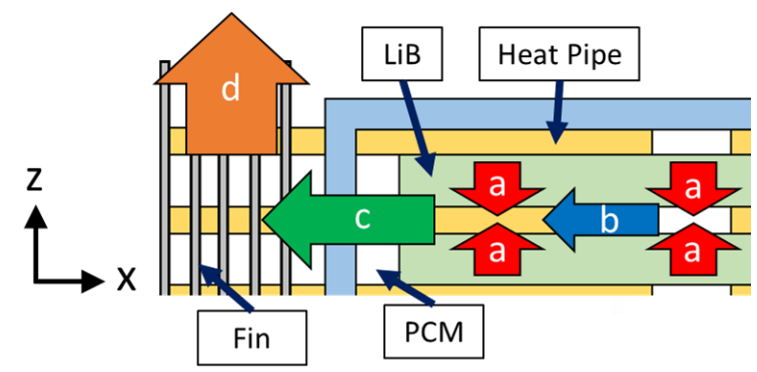

Fig. 5 Heat flow of the cooling system. (a) From LiB to PCM and HP; (b) From PCM to HP; (c) From HP to Fin; (d) From Fin to Air.

\subsection{Experimental method}

In this experiment, it was assumed that one of four $\mathrm{LiB}$ in the device suddenly increased in temperature due to abnormal heat generation, and the cooling performance of the system at that time was verified. One $\mathrm{LiB}$ in the center of the cooling device was externally short circuited. One $\mathrm{LiB}$ with a state of charge (SoC) of 100\% and three with SoCs of $0 \%$ were used in. SoC is the ratio of the amount of electricity charged to the electric capacity of the battery. As in the preliminary experiment, external short circuiting was done by connecting one LiB to the magnetic contactor. The state of the constructed circuit is shown in Fig. 6. In the preliminary experiment, as shown in Fig. 3, expansion started at the time when the LiB-surface temperature reached $90{ }^{\circ} \mathrm{C}$ and finally the LiB thickness became 5 to 6 times its initial value. In LiB short circuit experiments using the cooling system, LiB expanded and the whole cooling system could be broken. Therefore, for safety reasons, the experiment was terminated when the $\mathrm{LiB}$ temperature reached approximately $90{ }^{\circ} \mathrm{C}$ under all conditions.

In addition to experimentation using the cooling system, three other experiments were conducted for comparison. Experimental conditions were (1)-(4) below:

(1) Cooling with both PCM and HP: the cooling system shown in Fig. 4. (PCM \& HP);

(2) Cooling with PCM only: a state in which only RT50 was incorporated in the cooling system. (PCM only);

(3) Cooling with HP only: a state in which only HP was incorporated in the cooling system; since RT 50 was not incorporated, LiB was in contact with air. (HP only);

(4) Natural air cooling: neither RT 50 nor HP were used; since the LiB cells cannot stand by themselves without 
RT50 or HP, spacers (size: $240 \mathrm{~mm} \times 8 \mathrm{~mm} \times 2 \mathrm{~mm}$, made of acrylic) were inserted between LiB (without cooling).

The measurement positions of the LiB temperature and loading position of the LiB to be externally short-circuited in the experiment are shown in Fig. 7. The temperature-measurement positions of the LiB were set in the vicinity of the negative electrode and the central point on the surface of the LiB, respectively. In the preliminary experiment, the temperature in the vicinity of the negative electrode of LiB was that temperature rising was the fastest when LiB was short-circuited and the temperature in the center of $\mathrm{LiB}$ was the highest temperature in short circuit. The results shown in the following figures correspond to the highest temperature among these two positions, although the difference between the two was only a few degrees. As in the preliminary experiment, K-type sheath thermocouples were used for temperature measurement and GRAPHTEC GL820 was used as a data logger. Temperature changes were recorded at 2 second intervals.

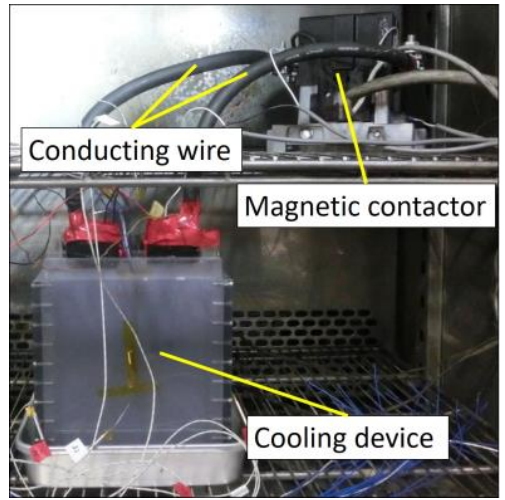

(a)

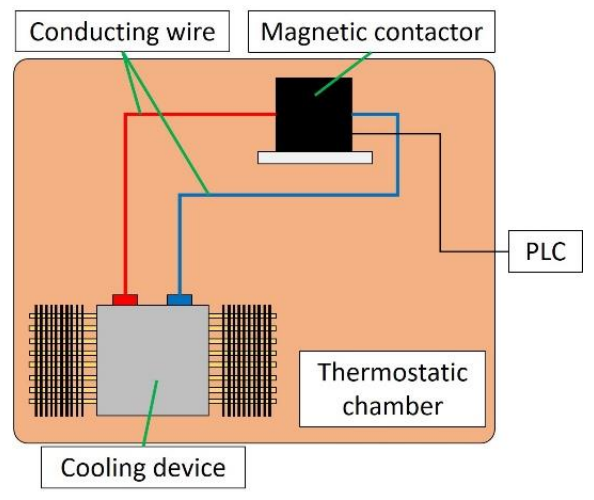

(b)

Fig. 6 Experimental equipment in the thermostatic chamber (a) Photo, (b) Schematic view.

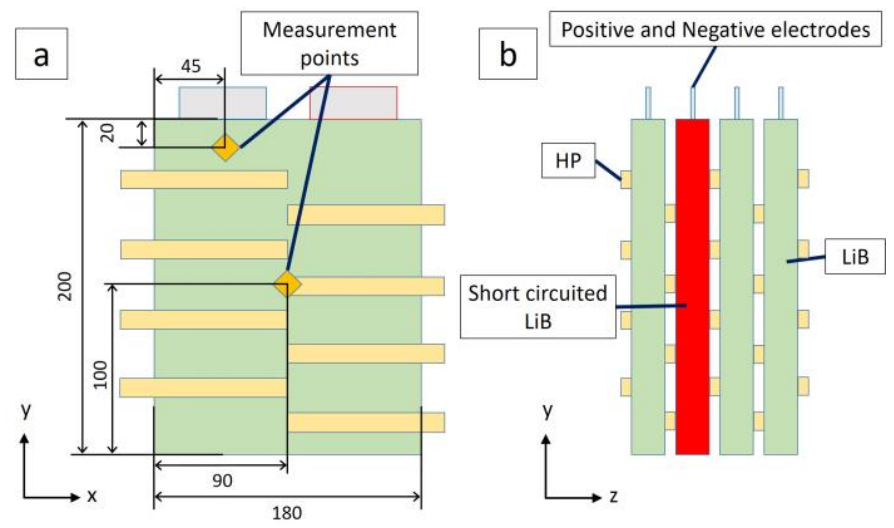

Fig. 7 Position of the LiB to be short circuited and measurement points in the experiment (a) Front view, (b) Side view.

\section{Numerical model and calculation condition 3.1 Numerical model}

In order to evaluate the performance of the cooling system, ANSYS Fluent Ver. 17.0 (CFD software) was used and thermal conduction was mainly calculated. Numerical models used in this calculation are shown in Figs. 8 and 9 . These models have the same dimensions and arrangement of parts as the experimental setup. Two sets of numerical models were used, one with HP and one without. The mesh data for this calculation are shown in Tables 1 and 2, respectively.

The measurement positions of LiB temperature in this calculation are shown in Fig. 10. In this calculation, it was found that the increasing behavior of LiB temperature differed from that in the experiment. Therefore, it was at first unknown which point of $\mathrm{LiB}$ would indicate the highest temperature; thus, three points were added to the measurement points of the temperature in the calculation. 


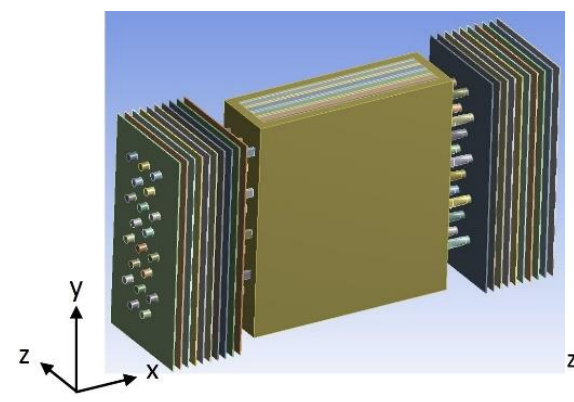

(a)

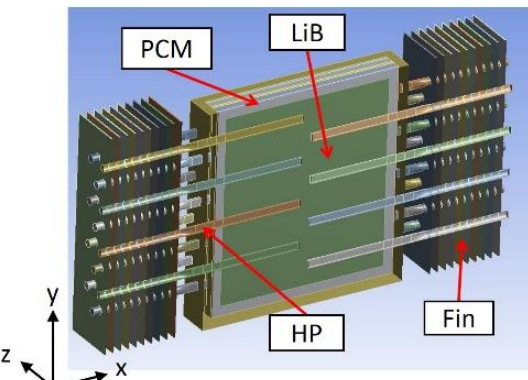

(b)

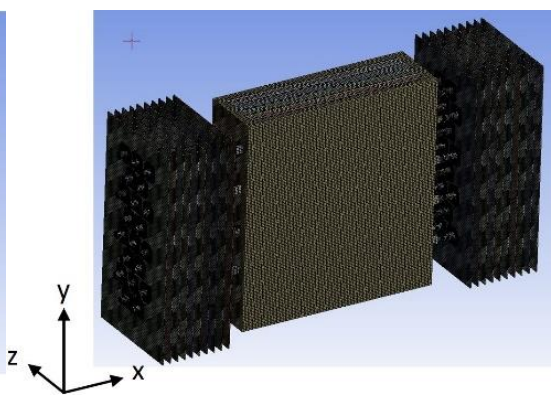

(c)

Fig. 8 Numerical model with HP (a) Over view, (b) Cross section, (c) Meshes of the model.

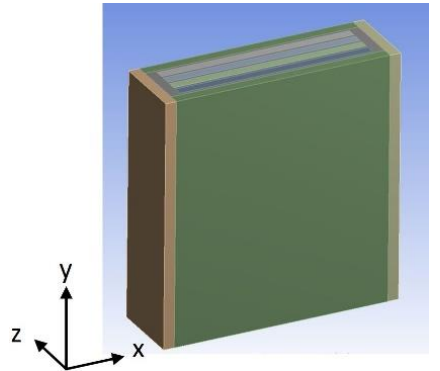

(a)

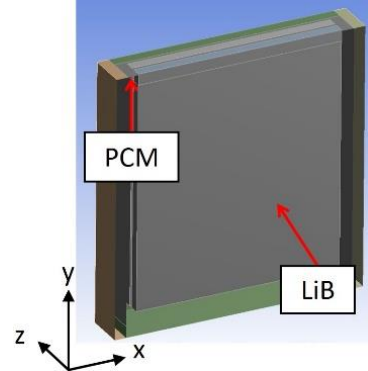

(b)

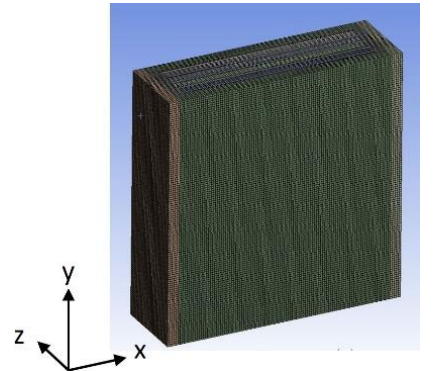

(c)

Fig. 9 Numerical model without HP (a) Over view, (b) Cross section, (c) Meshes of the model.

Table 1 Mesh data (With HP model).

\begin{tabular}{c|c}
\hline \hline Minimum mesh size $[\mathrm{mm}]$ & 1.0 \\
\hline Maximum mesh size $[\mathrm{mm}]$ & 2.0 \\
\hline Shape of mesh & Hexahedron \\
\hline Number of element & 977,035 \\
\hline
\end{tabular}

Table 2 Mesh data (Without HP model).

\begin{tabular}{c|c}
\hline \hline Minimum mesh size $[\mathrm{mm}]$ & 1.0 \\
\hline Maximum mesh size $[\mathrm{mm}]$ & 2.0 \\
\hline Shape of mesh & Hexahedron \\
\hline Number of element & 446,600 \\
\hline
\end{tabular}

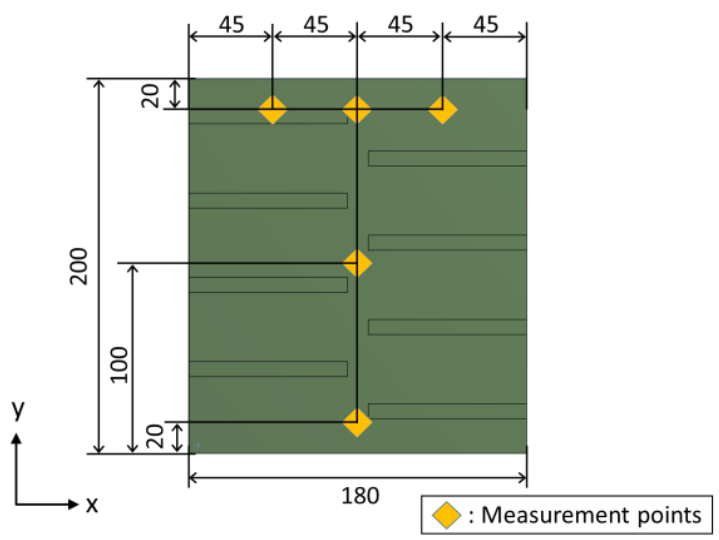

Fig. 10 Sizes of the LiB cell to be short circuited and measurement points in the calculation.

\subsection{Physical properties, boundary condition, and calculation condition}

Physical property values used in this numerical model are shown in Tables 3 to 7 . The heat-transfer coefficients of the fin, PCM, and container surfaces are shown in Table 8 . The property values for copper, polyvinyl chloride, aluminum, and PCM (RT50) at $25.0^{\circ} \mathrm{C}$ were used for the HP, container, fins, and PCM, respectively. The value of the effective thermal conductivity of the HP was set to 30 times larger than the thermal conductivity of copper $(398 \mathrm{~W} /(\mathrm{m} \cdot \mathrm{K}))$. As the physical-property values of the $\mathrm{LiB}$, the estimated values provided by Uzushio Electric Co., Ltd. were used. 
Table 3 Physical properties of LiB.

\begin{tabular}{c|c}
\hline \hline Density $\left[\mathrm{kg} / \mathrm{m}^{3}\right]$ & 2179 \\
\hline Specific heat $[\mathrm{J} /(\mathrm{kg} \cdot \mathrm{K})]$ & 1016.4 \\
\hline Thermal conductivity $[\mathrm{W} /(\mathrm{m} \cdot \mathrm{K})]$ & 8 \\
\hline
\end{tabular}

Table 5 Physical properties of fins.

\begin{tabular}{c|c}
\hline \hline Density $\left[\mathrm{kg} / \mathrm{m}^{3}\right]$ & 2719 \\
\hline Specific heat $[\mathrm{J} /(\mathrm{kg} \cdot \mathrm{K})]$ & 871 \\
\hline Thermal conductivity $[\mathrm{W} /(\mathrm{m} \cdot \mathrm{K})]$ & 202.4 \\
\hline
\end{tabular}

Table 7 Physical properties of PCM.

\begin{tabular}{c|c}
\hline \hline Density $($ at $322 \mathrm{~K})\left[\mathrm{kg} / \mathrm{m}^{3}\right]$ & 880 \\
\hline Density $($ at $353 \mathrm{~K})\left[\mathrm{kg} / \mathrm{m}^{3}\right]$ & 760 \\
\hline Specific heat $[\mathrm{J} /(\mathrm{kg} \cdot \mathrm{K})]$ & 2000 \\
\hline Thermal conductivity $[\mathrm{W} /(\mathrm{m} \cdot \mathrm{K})]$ & 0.2 \\
\hline Viscosity $[\mathrm{kg} /(\mathrm{m} \cdot \mathrm{s})]$ & 0.0237 \\
\hline Pure solvent melting heat $[\mathrm{kJ} / \mathrm{kg}]$ & 160 \\
\hline Solids temperature $[\mathrm{K}]$ & 322.15 \\
\hline Liquids temperature $[\mathrm{K}]$ & 322.15 \\
\hline
\end{tabular}

Table 4 Physical properties of heat pipes.

\begin{tabular}{c|c}
\hline \hline Density $\left[\mathrm{kg} / \mathrm{m}^{3}\right]$ & 2857 \\
\hline Specific heat $[\mathrm{J} /(\mathrm{kg} \cdot \mathrm{K})]$ & 381 \\
\hline Thermal conductivity $[\mathrm{W} /(\mathrm{m} \cdot \mathrm{K})]$ & 11940 \\
\hline
\end{tabular}

Table 6 Physical properties of container (Polyvinyl chloride).

\begin{tabular}{c|c}
\hline \hline Density $\left[\mathrm{kg} / \mathrm{m}^{3}\right]$ & 1450 \\
\hline Specific heat $[\mathrm{J} /(\mathrm{kg} \cdot \mathrm{K})]$ & 1000 \\
\hline Thermal conductivity $[\mathrm{W} /(\mathrm{m} \cdot \mathrm{K})]$ & 0.167 \\
\hline
\end{tabular}

Table 8 Boundary conditions

(Heat-transfer coefficients).

\begin{tabular}{c|c}
\hline \hline Cooler of fin $\left[\mathrm{W} /\left(\mathrm{m}^{2} \cdot \mathrm{K}\right)\right]$ & 5.0 \\
\hline Top of PCM $\left[\mathrm{W} /\left(\mathrm{m}^{2} \cdot \mathrm{K}\right)\right]$ & 4.0 \\
\hline Outer of case $\left[\mathrm{W} /\left(\mathrm{m}^{2} \cdot \mathrm{K}\right)\right]$ & 4.0 \\
\hline
\end{tabular}

There are contact thermal resistances on the boundary surfaces of the LiB, HP, PCM, and the like. Therefore, calculation was performed to estimate contact thermal resistance. According to Fourier's law, the heat-flux equation is Eq. (2), from which we obtain Eq. (3),

$$
\begin{aligned}
& q=k \frac{\Delta T}{l} \\
& q=\frac{\Delta T}{(l / k)}
\end{aligned}
$$

Here, $q\left[\mathrm{~W} / \mathrm{m}^{2}\right]$ is the heat flux passing through an object, $k[\mathrm{~W} /(\mathrm{m} \cdot \mathrm{K})]$ is the thermal conductivity of the object, $\Delta T$ $[\mathrm{K}]$ is the temperature difference in the object, and $l[\mathrm{~m}]$ is the object's thickness. The denominator $l / k$ of equation (2) is defined as the object's thermal resistance. In ANSYS Fluent, contact-thermal resistance can be set by applying this value to the boundary surface between any objects. In this case, $l$ is the imaginary thickness of the boundary interface and $k$ is the thermal conductivity of the boundary substance. Here, the contact-thermal resistance of the boundary surface was set and calculation was done as described above. In this calculation, a thermal conductivity of $0.2 \mathrm{~W} /(\mathrm{m} \cdot \mathrm{K})$ was set as the value for the virtual thickness substance. This is the same value as the thermal conductivity of the PCM used in the experiment. The contact-thermal-resistance values used in the calculation are shown in Table 9.

Table 9 Contact-thermal resistance (Using a PCM model).

\begin{tabular}{c|c|c}
\hline \hline Interface between two objects & Wall thickness $[\mathrm{mm}]$ & Value $\left[\left(\mathrm{m}^{2} \cdot \mathrm{K}\right) / \mathrm{W}\right]$ \\
\hline LiB - Heat Pipe & 0.3 & 0.0015 \\
\hline LiB - PCM & 1.2 & 0.006 \\
\hline HP - PCM & 0.1 & 0.0005 \\
\hline PCM - Container & 0.4 & 0.002 \\
\hline
\end{tabular}

The numerical calculation was performed in the case where LiB was externally short circuited to represent abnormal heat generation corresponding to the experiment by giving a large heat generation to one of the four LiB. In the simulation of the PCM material, the thermal conduction and solid-liquid phase change were considered. The convection of melted PCM was neglected for simplicity. 


\subsection{Heat generation setup}

In ANSYS Fluent, users can customize various conditions necessary for calculation by setting user-defined functions. In this calculation, some user-defined functions were used as source terms. When using user-defined functions, it is necessary to set mathematical-function expressions.

For calculation of experiment using PCM, independently set mathematical functions were used as the heat-generation source. Graphs comparing the functions of heat generation and its temporal change in the LiB in the preliminary experiment are shown in Fig. 11. As can be seen from Fig. 11, the temporal change in the heat generation obtained from the preliminary experiment was found to be very complicated. At first, the temporal-change equation of heat generation, which reproduced these data faithfully, was used in the calculation. In the preliminary experiment, the temperature was measured in open atmosphere without constraint on the LiB shape; then, the heat generation was estimated from the measured data. However, in this short circuit experiment, LiB cells were inserted into a container holding heat-absorbing parts such as PCM and HP. Therefore, the temperature change in this experiment was not successfully reproduced, even if the temporal change of heat generation obtained from the preliminary experiment was used. Thus, temperature-change equations adjusted to the short circuit experiment were necessary. The following functions were obtained by considering the tendency in the preliminary experiment and by adjusting them to reproduce the temperature obtained in the shortcircuit experiment (in this case, with PCM only and PCM \& HP). These functions were divided into two parts, from zero to 30 seconds from the start of short circuiting and after 30 seconds, and are respectively shown as Eqs. (4) and (5):

$$
\begin{array}{ll}
S=\frac{500000}{0.002 t+0.12}-250000 & (0[\mathrm{~s}]<\mathrm{t}<30[\mathrm{~s}]) \\
S & =\frac{250000}{0.00096 t+0.12}-50000 \quad(30[\mathrm{~s}]<\mathrm{t})
\end{array}
$$

Here, $S\left[\mathrm{~W} / \mathrm{m}^{3}\right]$ is the heat generation per unit volume and $t[\mathrm{sec}]$ is the elapsed time. Since these are dictated for Fluent, heat generation is the value per unit volume. A plot of these functional expressions is also shown in Fig. 11. Although there is some difference between the two plots, as we stated, this is a result of adjustments to reproduce the experimentally measured temperature in the container.

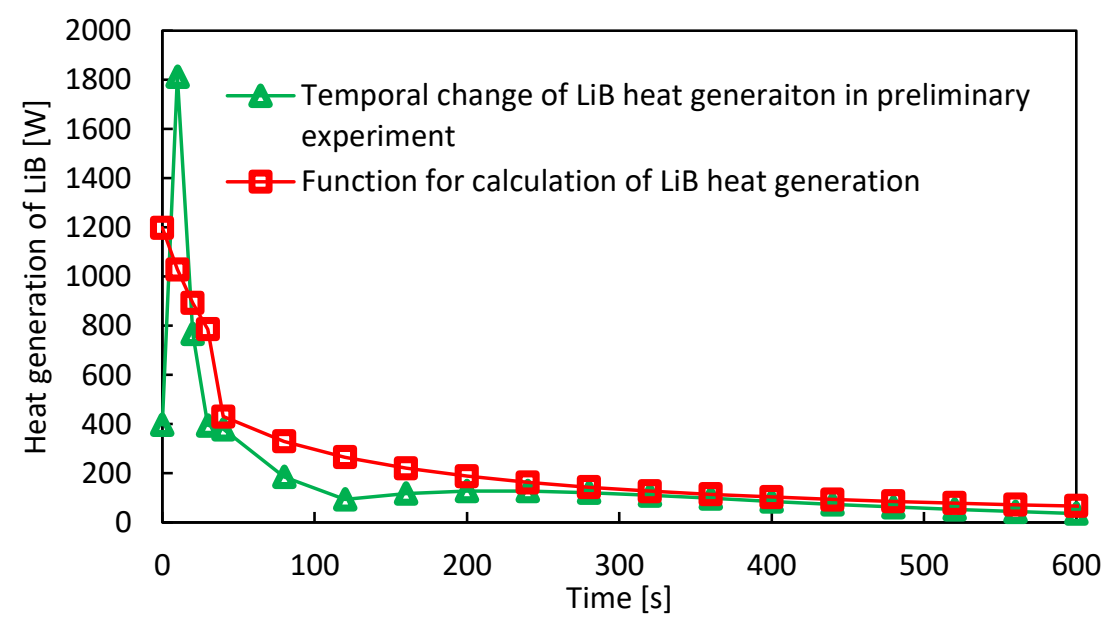

Fig. 11 Temporal change data of LiB heat generation in the preliminary experiment and the adjusted function for calculation.

\section{Results and discussions \\ 4.1 Experimental results}

The time series of LiB-temperature rise from the start of short circuiting under each condition are shown in Fig. 12. At 30 seconds under the "HP only" and "without cooling" conditions, the maximum temperatures of $\mathrm{LiB}$ became $91.3{ }^{\circ} \mathrm{C}$ 
and $89.9^{\circ} \mathrm{C}$, respectively. Therefore, the experiment was stopped at this point for safety reasons. At this time, in the "PCM \& HP" and "PCM only" cases, the temperatures of the LiB were $55.0^{\circ} \mathrm{C}$ and $60.2{ }^{\circ} \mathrm{C}$, respectively. The cooling effects by HP only and without cooling were confirmed to be insufficient under extremely large heat generation due to external short circuiting. On the other hand, for PCM \& HP and PCM only, it was confirmed that the maximum temperature of the $\mathrm{LiB}$ up to 30 seconds from the start could be suppressed to about $60^{\circ} \mathrm{C}$. From this reason, cooling by PCM can be said to be effective for preventing sudden temperature rise in the initial stage of short circuiting the LiB.

The results of the temperature change of $\mathrm{LiB}$ when $\mathrm{LiB}$ was short-circuited for a long time in the "PCM \& HP" and "PCM only" cases are shown in Table 10. Moreover, the time until the temperature of LiB reached $80{ }^{\circ} \mathrm{C}$ is shown in Table 11 and the maximum temperature of the $\mathrm{LiB}$ is shown in Table 12. Using only PCM, LiB temperature reached $80^{\circ} \mathrm{C}$ in 88 seconds after starting to short circuit and reached a maximum temperature of $92.5^{\circ} \mathrm{C}$ in 200 seconds. In PCM $\& \mathrm{HP}, \mathrm{LiB}$ temperature reached $80{ }^{\circ} \mathrm{C}$ in 178 seconds after short circuiting started and reached a maximum temperature of $80.1^{\circ} \mathrm{C}$ in 182 seconds. Therefore, in the case of PCM \& HP, the time until the LiB temperature reached $80{ }^{\circ} \mathrm{C}$ was about two times longer than when using PCM only, and the maximum temperature was reduced by about $10{ }^{\circ} \mathrm{C}$. Moreover, comparing the temperature change between PCM \& HP and PCM only, temperature changes differed from about 30 seconds after starting short circuit and the temperature difference became noticeable at 50 to 100 seconds. The cooling effect by HP and the fins began to appear at that time. As a result, the maximum temperature of the LiB was suppressed to about $80{ }^{\circ} \mathrm{C}$. It is consider the temperature of the $\mathrm{LiB}$ to become dangerous at about $80{ }^{\circ} \mathrm{C}$ (Yamada et al., 2017), and from this experimental result, it can be said that the prototype cooling system prevented temperature from becoming dangerous during short circuiting for a long time. Thus it was confirmed that the combination of PCM and HP is effective for preventing rapid temperature rise of the $\mathrm{LiB}$, experimentally.

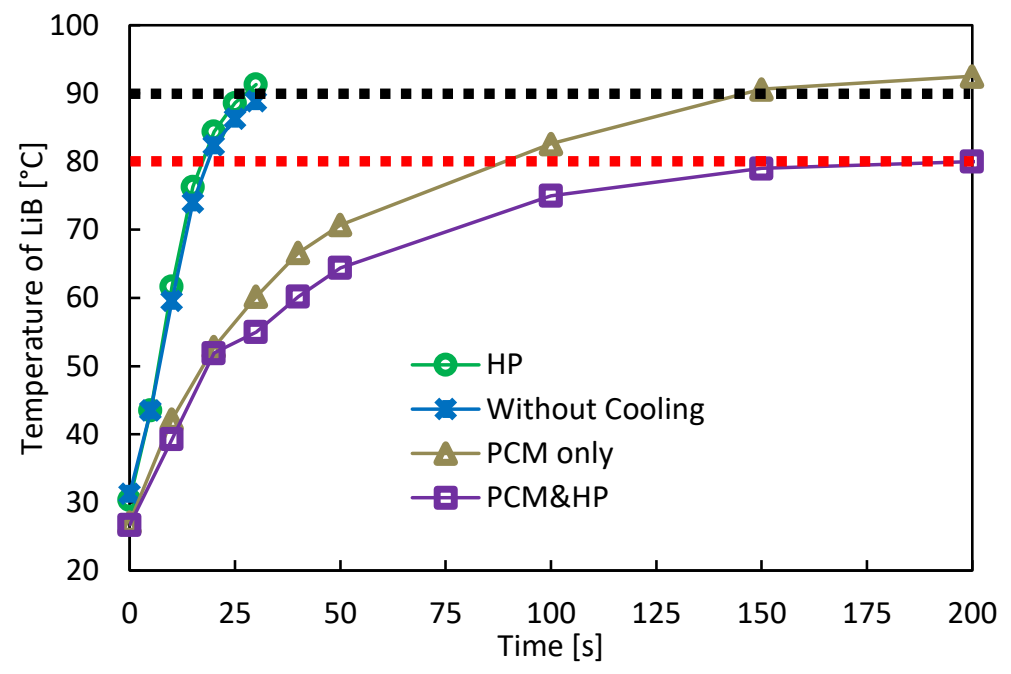

Fig. 12 Comparison of LiB temperature under four experimental conditions, with $80{ }^{\circ} \mathrm{C}$ (red) and $90{ }^{\circ} \mathrm{C}$ (black) lines overlaid.

Table 10 Temporal change of LiB temperature in experiment.

\begin{tabular}{c|c|c}
\hline \hline \multirow{2}{*}{ Time $[\mathrm{s}]$} & \multicolumn{2}{|c}{ Temperature $\left[{ }^{\circ} \mathrm{C}\right]$} \\
\cline { 2 - 3 } & PCM & PCM\&HP \\
\hline 0 & 27.1 & 26.7 \\
\hline 10 & 42.2 & 39.3 \\
\hline 20 & 52.8 & 51.9 \\
\hline 30 & 60.2 & 55.0 \\
\hline 50 & 70.7 & 64.4 \\
\hline 100 & 82.6 & 75.0 \\
\hline 150 & 90.6 & 79.0 \\
\hline 200 & 92.5 & 80.0 \\
\hline
\end{tabular}


Table 11 Time until reaching $80^{\circ} \mathrm{C}$.

\begin{tabular}{c|c|c|c|c}
\hline \hline & HP & $\begin{array}{c}\text { Without } \\
\text { Cooling }\end{array}$ & $\begin{array}{c}\text { PCM } \\
\text { only }\end{array}$ & PCM\&HP \\
\hline Time [s] & 17 & 19 & 88 & 178 \\
\hline
\end{tabular}

Table 12 Maximum temperature of the LiB using PCM\&HP and PCM only.

\begin{tabular}{c|c|c}
\hline \hline & PCM only & PCM\&HP \\
\hline Temperature $\left[{ }^{\circ} \mathrm{C}\right]$ & 92.5 & 80.1 \\
\hline
\end{tabular}

\subsection{Calculation results}

\subsubsection{Comparison with experimental results}

Our experimental results confirm that "PCM \& HP" and "PCM only," among the experimental conditions used in this study, were effective against rapid temperature rise of the LiB. Therefore, the temperature change of the LiB was simulated only in the two models corresponding to PCM \& HP and PCM only, with Eqs. (3) and (4) used to model heat generation in the LiB. To analyze the calculation results, the temperature at the position of the lowest height among the five measurement positions in Fig. 10 was adopted, as the temperature at this position indicated the highest value in the calculation, which will be shown later in Figs. 17 (b), (c) and (d). This could be thought reasonable due to the difference in the manner of heating between the experiment and the simulation. In the experiment, the heating distribution was determined by the inner-current distribution, whereas in the calculation, the heat generation was uniformly given to the whole volume since the current distribution was difficult to predict. In this study, we discuss the maximum temperature of the LiB. Therefore, we simply adopted the highest temperature in the LiB regardless of its position. Calculation and experimental results are compared in Fig. 13 and Table 13, respectively. Moreover, the time needed for the temperature of the $\mathrm{LiB}$ to reach $80^{\circ} \mathrm{C}$ and the maximum temperature of the $\mathrm{LiB}$ are shown in Tables 14 and 15 , respectively. As can be seen from Fig. 13, in PCM \& HP, the temperature changes of the LiB in the calculation and the experiment tended to be very similar. Similar results were obtained for PCM only too. For this reason, it can be said that results consistent with experimental values were reproduced by Eqs. (3) and (4) for heat generation by the LiB and by adjusting them with numerical models. Also, since both cases of PCM \& HP and PCM only were loaded with PCM, the temperature rise of the LiB was suppressed in the case of PCM \& HP because the heat generated by the LiB was released outside by the HP.

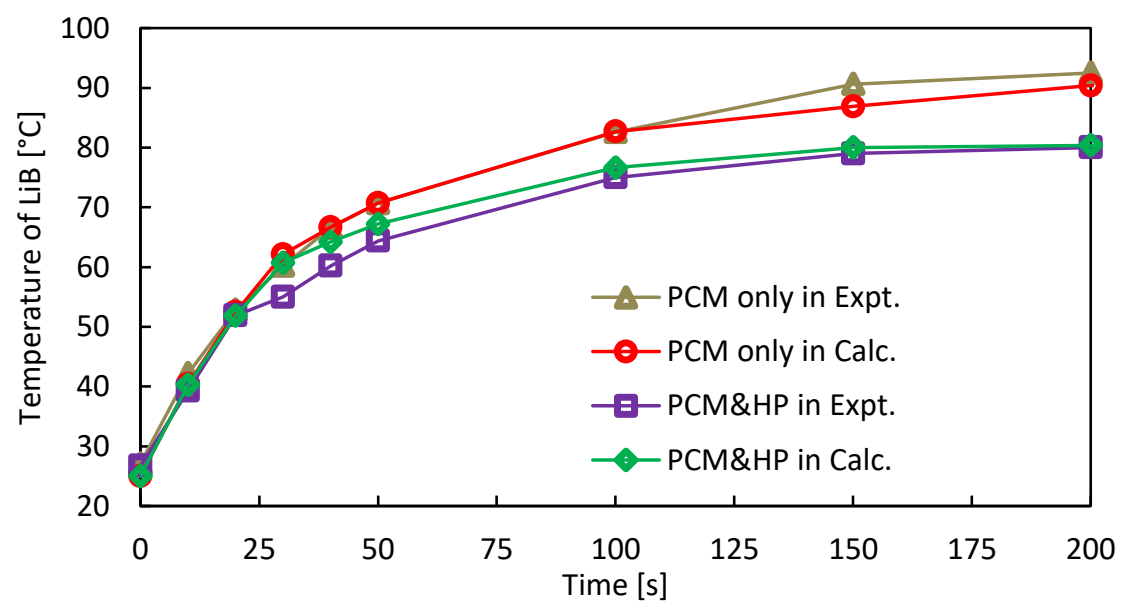

Fig. 13 Comparison of LiB temperature between experiments and calculations.

Table 13 Temporal change of LiB temperature in experiments and calculations.

\begin{tabular}{c|c|c|c|c}
\hline \hline \multirow{2}{*}{ Time [s] } & \multicolumn{4}{|c}{ Temperature [ $\left.{ }^{\circ} \mathrm{C}\right]$} \\
\cline { 2 - 5 } & \multicolumn{2}{|c}{ PCM only } & \multicolumn{2}{c}{ PCM+HP } \\
\cline { 2 - 5 } & Experiment & Calculation & Experiment & Calculation \\
\hline 0 & 27.1 & 25.0 & 26.7 & 25.0 \\
\hline 50 & 70.7 & 70.7 & 64.4 & 67.2 \\
\hline 100 & 82.6 & 82.7 & 75.0 & 76.6 \\
\hline 150 & 90.6 & 86.9 & 79.0 & 80.0 \\
\hline 200 & 92.5 & 90.4 & 80.0 & 80.4 \\
\hline
\end{tabular}


Table 14 Time until reaching $80^{\circ} \mathrm{C}$.

\begin{tabular}{c|c|c|c|c}
\hline \hline \multirow{2}{*}{} & \multicolumn{2}{|c|}{ PCM only } & \multicolumn{2}{c}{ PCM\&HP } \\
\cline { 2 - 5 } & Expt. & Calc. & Expt. & Calc. \\
\hline Time [s] & 88 & 83 & 178 & 151 \\
\hline
\end{tabular}

Table 15 Maximum temperature of the LiB.

\begin{tabular}{c|c|c|c|c}
\hline \hline & \multicolumn{2}{|c|}{ PCM only } & \multicolumn{2}{c}{ PCM\&HP } \\
\cline { 2 - 5 } & Expt. & Calc. & Expt. & Calc. \\
\hline Temperature $\left[{ }^{\circ} \mathrm{C}\right]$ & 92.8 & 92.5 & 80.1 & 80.5 \\
\hline
\end{tabular}

\subsubsection{Effect of PCM}

We here state the details of the effect of PCM in the cooling system during external short circuiting of a LiB. The calculation results of the temperature changes of the LiB, PCM, HP, and fin in the PCM \& HP model, and of the LiB and PCM in the PCM only model, are shown in Fig. 14 and Table 16, respectively. The representative temperatures in Fig. 14 and Table 16 were collected and adopted at the following positions, respectively, because we wanted our comparisons to be clear and meaningful. In the PCM \& HP model, the temperatures of the LiB and PCM were at the lowest height among the five measurement positions in Fig. 10. The temperature of the HP was measured at the heat pipe in contact with the highest position of the $\mathrm{LiB}$, and that of the fin was at the fin plate closest to the cooling device and on its center line in the plate area. In the PCM only model, the temperatures of the LiB and PCM were at the center of the LiB.

In both the PCM \& HP and PCM only models, the temperature of the LiB sharply increased immediately after short circuiting started. Then, it can be seen that the temperature rise of the PCM occurred earlier than that of the HP or fins in the PCM \& HP case. It is thought that the heat released from the LiB moved to PCM rather than HP immediately after short circuiting. In addition, since the temperature rise of the HP and fins was small, the temperature difference between the fins and the outside air was also small and so too was the amount of heat released to the outside air.

The amounts of heat transferred from the LiB to the HP and from the LiB to the PCM in the PCM \& HP model, the sum of these values, and the amounts of heat transferred from the LiB to the PCM in the PCM only model are shown in Fig. 15. The data of amounts of heat transferred were directly obtained from the calculation results of ANSYS Fluent. From Fig.15, it can be seen that the amount of heat transferred from the LiB to the PCM immediately after short circuiting started was larger than that transferred from the LiB to the HP in the PCM \& HP case, due to the differences in contact area between the LiB and the HP and PCM. The LiB-PCM contact area was about four times larger than the LiB-HP one. Therefore, the amount of heat transferred from the LiB to the PCM was larger. The amount of heat transferred from the $\mathrm{LiB}$ to the HP after 50 seconds of short circuiting exceeded that transferred from the LiB to the PCM since heat transport by the HP increased. Moreover, as shown in Figs. 13 and 14, although the amount of heat transferred from the LiB to the PCM in the PCM only case was larger than that in the PCM \& HP case, the tendencies of PCM temperature and temperature change were almost the same under both conditions. In both cases, when the PCM reached the melting point, the temperature was effectively kept at this point. Thus, there was hardly any difference in PCM temperature at the point where data was taken. Also, from Fig. 15, it is seen that in PCM \& HP, after a certain time had elapsed from the start of short circuiting the LiB, the heat generation of the LiB moved to HP rather than to PCM. Therefore, it took some time for the heat transfer to the HP to increase, and it can be said that cooling by the PCM is more effective than by the HP at the initial stage of short circuiting.

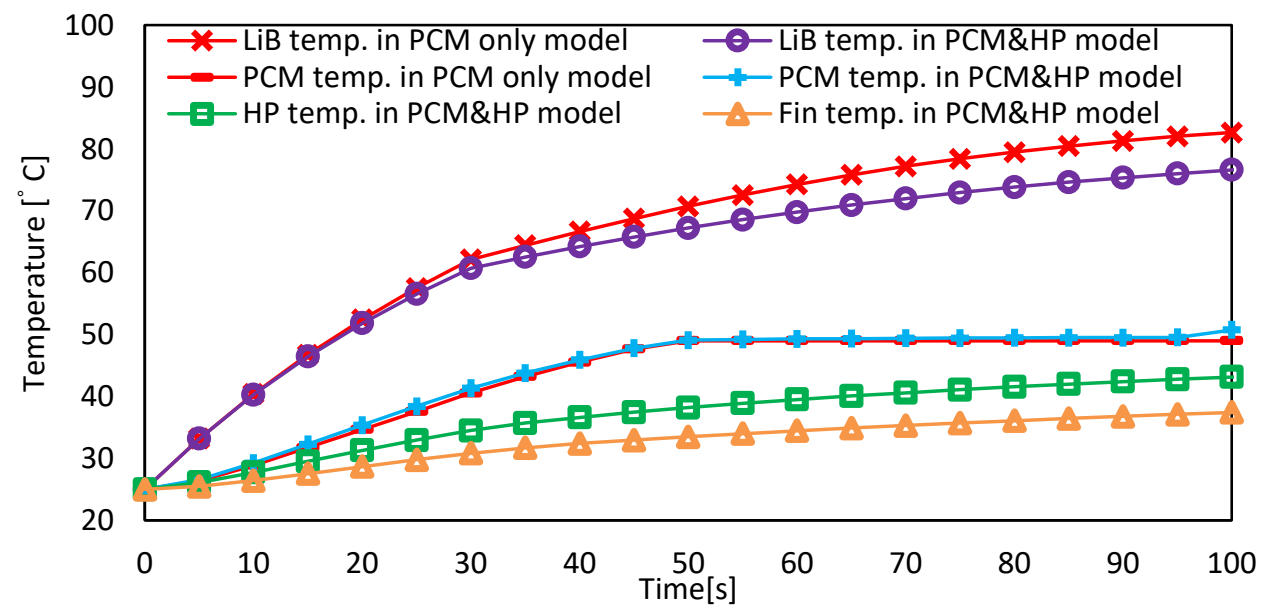

Fig. 14 Comparison of the LiB, PCM, HP and Fin temperatures between the PCM\&HP and PCM only model. 
Hata, Wada, Tatsuya Yamada, Hirata, Takashi Yamada and Ono,

Journal of Thermal Science and Technology, Vol.13, No.2 (2018)

Table 16 Temporal change of LiB, PCM, HP and Fin temperature in the PCM\&HP and PCM only models.

\begin{tabular}{c|c|c|c|c|c|c}
\hline \multirow{2}{*}{ Time $[\mathrm{s}]$} & \multicolumn{5}{|c}{ Temperature $\left[{ }^{\circ} \mathrm{C}\right]$} \\
\cline { 2 - 7 } & \multicolumn{5}{|c|}{ PCM\&HP model } & \multicolumn{2}{c}{ PCM only model } \\
\cline { 2 - 7 } & LiB & PCM & HP & Fin & LiB & PCM \\
\hline 0 & 25.0 & 25.0 & 25.0 & 25.0 & 25.0 & 25.0 \\
\hline 10 & 40.3 & 29.2 & 27.7 & 26.4 & 40.4 & 28.9 \\
\hline 20 & 51.8 & 35.4 & 31.3 & 28.7 & 52.4 & 34.7 \\
\hline 30 & 60.7 & 41.3 & 34.5 & 30.8 & 62.1 & 40.6 \\
\hline 50 & 67.2 & 49.0 & 38.2 & 33.5 & 70.7 & 49.0 \\
\hline 100 & 76.6 & 49.5 & 43.1 & 37.4 & 82.7 & 49.1 \\
\hline
\end{tabular}

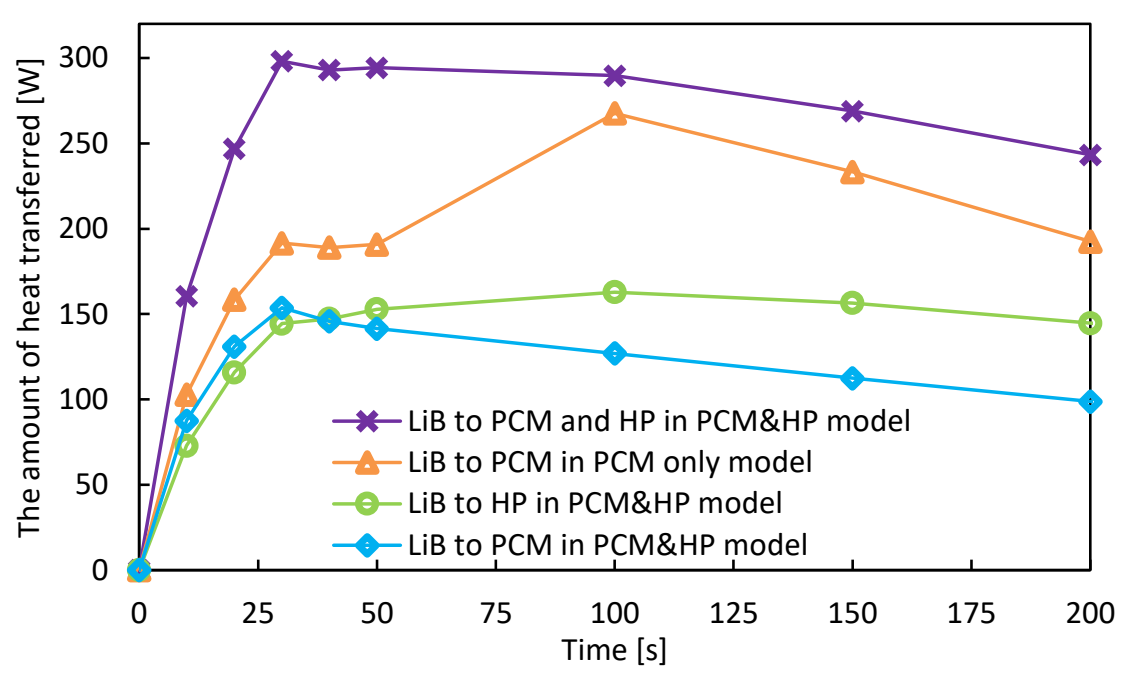

Fig. 15 Amount of heat transferred from the LiB to the HP or PCM in the PCM\&HP and PCM only models.

\subsubsection{Effects of HP}

Here, we look at the effect of HP in the cooling system under external short circuiting of a LiB. From Table 12, it was confirmed that the time required for the maximum temperature of the $\mathrm{LiB}$ to reach $80{ }^{\circ} \mathrm{C}$ in the experiment with PCM \& HP was 178 seconds, about twice as long as the 88 seconds needed in the PCM only case. Temperature distributions at 50 seconds, 100 seconds, 150 seconds and 200 seconds after the start of short circuiting in the XY section of the module in the PCM \& HP and PCM only models are shown in Figs. 17 and 18, respectively. The XY cross section was set to a position passing through the middle position of the thickness of the heated LiB. The XY section is shown in Fig. 16(a). As shown in Figs. 17 and 18, in the PCM \& HP models, there was some temperature difference between the part where the HP contacted the LiB and the part where it was not in contact with the LiB. On the contrary, in the PCM only case, there was a uniform temperature difference from the center of $\mathrm{LiB}$ to the outside. The temperature difference at this contact point started to be seen 50 seconds after short circuiting started, although the figure at less than 50 seconds is not shown here, and it became remarkable after 150 seconds. From this result, it can be said that the cooling effect by HP began to appear at about 50 seconds from the start of short circuiting. In addition, Fig. 15 shows that the total values of the heat transferred from the LiB to the PCM and to the HP in the PCM \& HP model exceeded that transferred from the LiB to the PCM in the PCM only case (as can be understood from Figs. 17 and 18) due to cooling effect of the HP. This may explain why the time until the $\mathrm{LiB}$ temperature reached $80{ }^{\circ} \mathrm{C}$ in the PCM \& HP case was extended over the PCM only case.

The temperature distributions at 50 seconds, 100 seconds, 150 seconds and 200 seconds of short circuiting in the ZX cross section of the module center in the PCM \& HP and PCM only models are shown in Figs. 19 and 20, respectively. The ZX cross section was set at a position passing through the middle of the height direction of the cooling system. The ZX cross section is shown in Fig. 16(b). From these results, it is seen that the heat moved faster throughout the module 
Hata, Wada, Tatsuya Yamada, Hirata, Takashi Yamada and Ono, Journal of Thermal Science and Technology, Vol.13, No.2 (2018)

in the container in the PCM \& HP case than in the PCM only case. This was because the heat transferred from the heated $\mathrm{LiB}$ was released from the fins and simultaneously passed through the adjacent HP through the fins to again move into the module and transfer into the adjacent LiB and its surrounding PCM. This is an interesting side effect of this HP system and may lead to effective use of the latent heat of the whole PCM inside the container. Thus, it can be said that the HP was performing effectively about 50 seconds after short circuiting started.

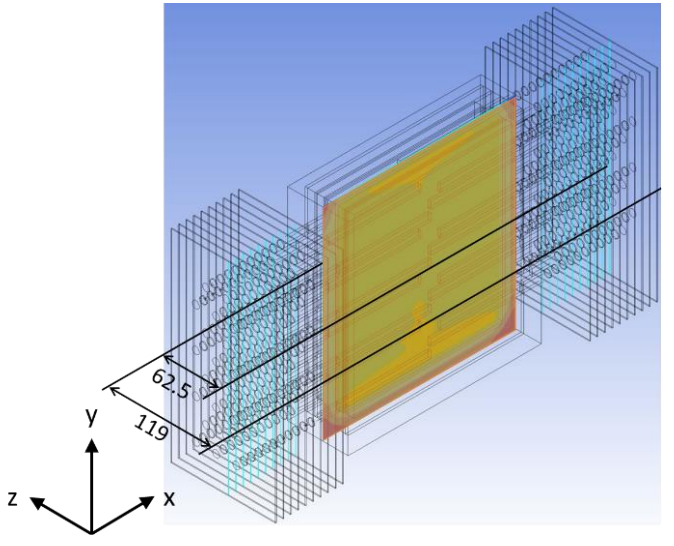

(a)

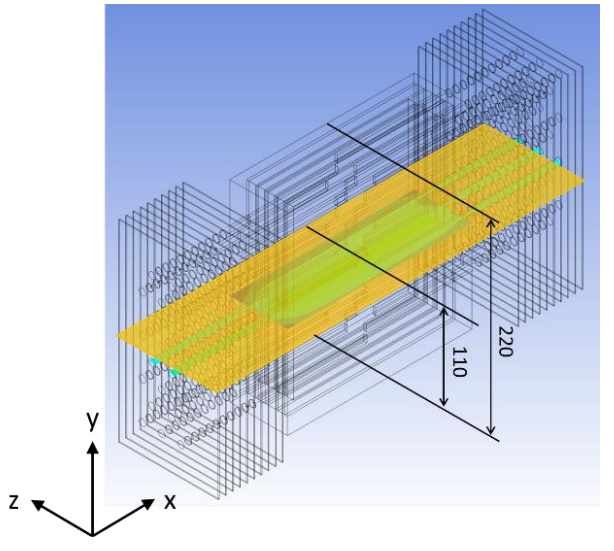

(b)

Fig. 16 Cross sections for the temperature distribution of each model (a) XY cross section, (b) ZX cross section.

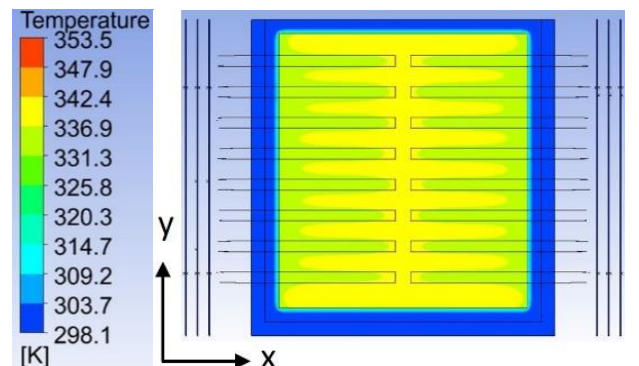

(a)

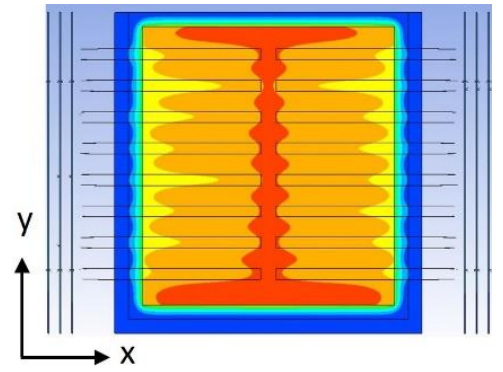

(c)

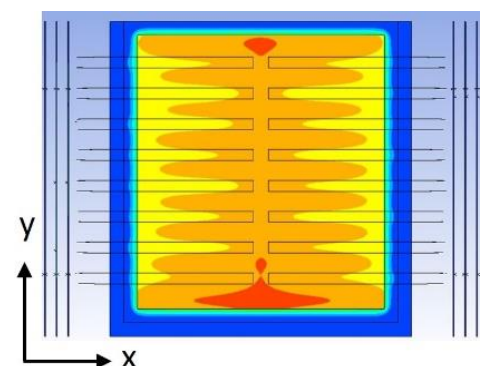

(b)

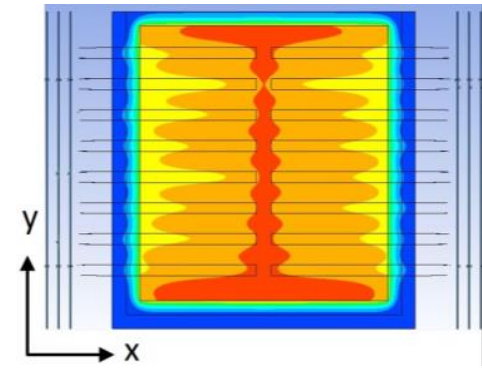

(d)

Fig. 17 Temperature distribution at XY cross section of the PCM\&HP model at (a) $50 \mathrm{~s}$, (b) $100 \mathrm{~s}$, (c) $150 \mathrm{~s}$ and (d) $200 \mathrm{~s}$. 
Hata, Wada, Tatsuya Yamada, Hirata, Takashi Yamada and Ono, Journal of Thermal Science and Technology, Vol.13, No.2 (2018)

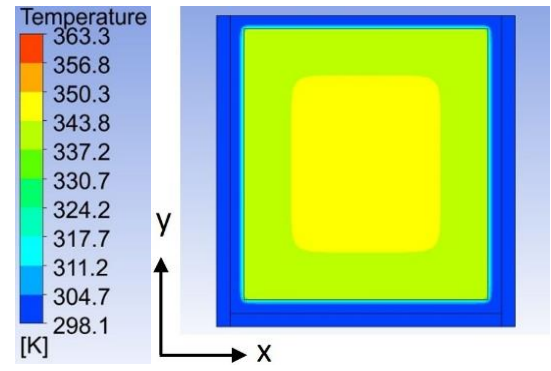

(a)

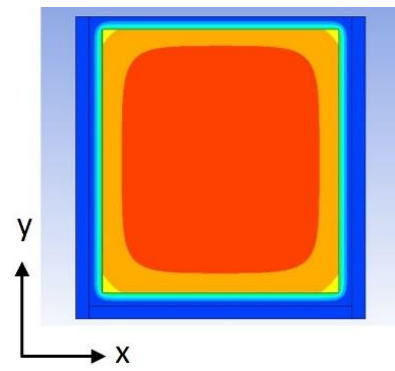

(c)

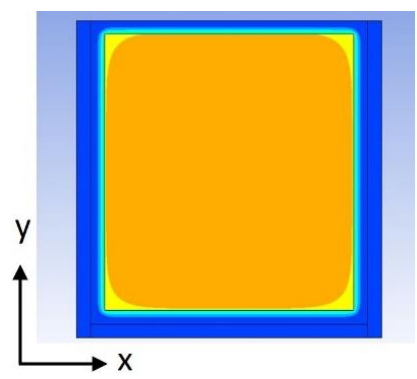

(b)

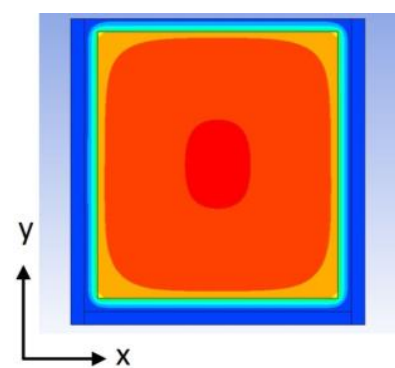

(d)

Fig. 18 Temperature distribution at XY cross section of the PCM only model at (a) $50 \mathrm{~s}$, (b) $100 \mathrm{~s}$, (c) $150 \mathrm{~s}$ and (d) $200 \mathrm{~s}$.

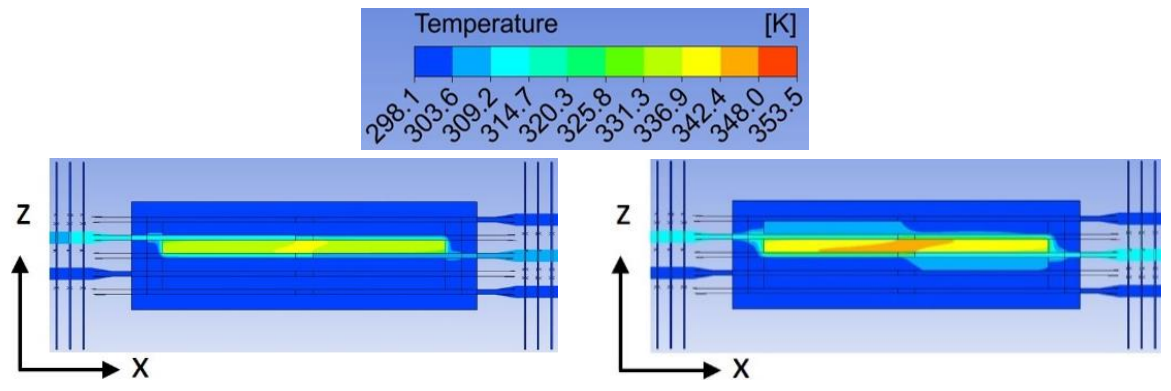

(a)

(b)
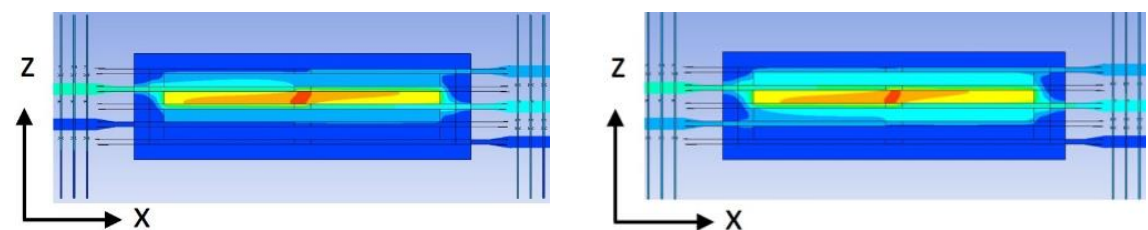

(c)

(d)

Fig. 19 Temperature distribution at ZX cross section of the PCM\&HP model (a) $50 \mathrm{~s}$, (b) $100 \mathrm{~s}$, (c) $150 \mathrm{~s}$ and (d) $200 \mathrm{~s}$. 


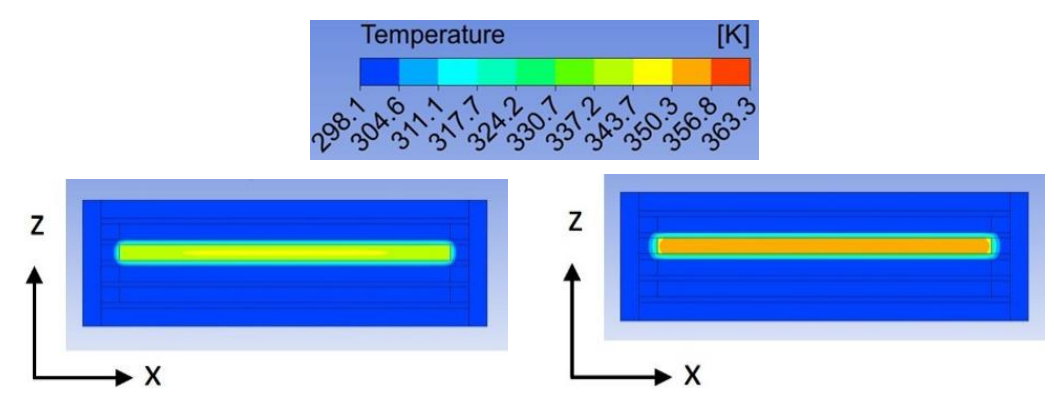

(a)

(b)

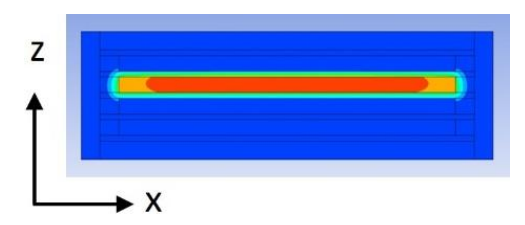

(c)

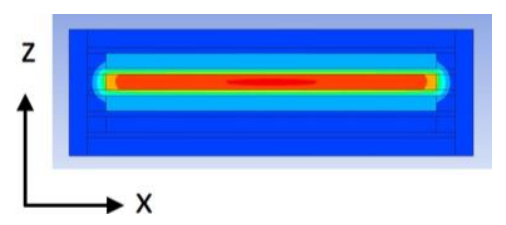

(d)

Fig. 20 Temperature distribution at ZX cross section of the PCM only model (a) $50 \mathrm{~s}$, (b) $100 \mathrm{~s}$, (c) $150 \mathrm{~s}$ and (d) $200 \mathrm{~s}$.

\subsubsection{Melting situation of PCM}

We here describe the PCM's melting situation during external short circuiting of the LiB. The temporal change of the PCM's melting rate in the PCM \& HP and PCM only models up to 200 seconds are shown in Fig. 21. The melting rate means the volumetric ratio of the melted amount of PCM to the total PCM volume. Comparing the melting rates under the two cases, that of the PCM \& HP case was larger. As shown in Figs. 19 and 20, the PCM-melting rate was thought to be higher in the PCM \&HP case than in the PCM only case because the heat released from LiB was transferred to the entire inside of the module more quickly for the former case.

The maximum PCM-melting rates at 200 seconds in the PCM \& HP and PCM only cases are shown in Table 17, respectively. In both cases, the maximum PCM-melting rate was less than $15 \%$. This was because the heat generation by the $\mathrm{LiB}$ decreased with the passage of time, and then there was insufficient heat to melt the whole PCM. Thus, there remains room for improvement in PCM-loading capacity and loading methods in the system in order to make more effective use of the latent heat of fusion of the PCM.

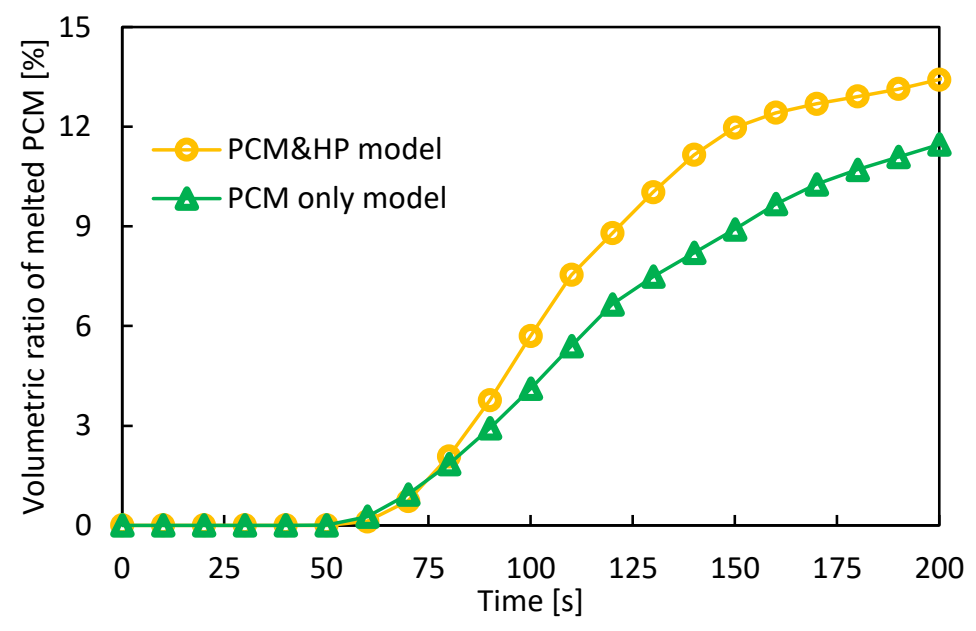

Fig. 21 Change of the volumetric ratio of melted PCM in the PCM\&HP and PCM only model until $200 \mathrm{~s}$.

Table 17 Maximum volumetric ratio of melted PCM to total PCM volume in the PCM\&HP and PCM only models.

\begin{tabular}{l|c|c}
\hline \hline & PCM only & PCM\&HP \\
\hline Maximum volumetric ratio of melted PCM [\%] & 11.5 & 13.4 \\
\hline
\end{tabular}




\section{Conclusion}

In this study, experiments and calculations were conducted on the cooling system devised and prototyped by Yamada et al. and the cooling performance under a rapid temperature rise when one LiB was externally short circuited was evaluated and verified. The following conclusions were confirmed.

1) It was found that LiB-temperature rise in the initial stage of short circuiting was suppressed more using PCM than without PCM. In particular, when PCM and HP were combined, the time until the temperature of the LiB reached $80^{\circ} \mathrm{C}$ was 178 seconds, and the LiB's temperature remained at around this value.

2) In the system with combined PCM and HP, it was thought from the calculation results that the heat generated from the $\mathrm{LiB}$ at the initial stage of short circuiting moved to the PCM rather than to the HP, and the LiB was cooled by the PCM's latent heat. It was confirmed that after about 50 seconds of short circuiting, the heat transported to HP became active and the cooling performance began to be promoted.

3) From the calculation results, it was confirmed that the melted PCM was less than 15\% of the total amount of PCM loaded in the system in both the PCM only and PCM \& HP cases. It is thought that there remains room for improvement for effective utilization of the PCM.

It was found that the LiB-cooling system consisting of a combination of PCM and HP used in this study can keep the temperature of the $\mathrm{LiB}$ at about $80^{\circ} \mathrm{C}$ or less, even during long-term short circuiting of one LiB cell. Therefore, this cooling performance seems to be effective against most situations that may actually be encountered. However, only about $15 \%$ of the PCM loaded in the cooling system was melted after 200 seconds of short circuiting, as shown by the calculation. Therefore, the latent heat of the PCM that did not melt was not effectively employed. It is thought that this is because the number of HP in this system, the loading capacity of the PCM, and the melting point were not welloptimized. Therefore, it is possible that the temperature rise of the LiB can be further suppressed by optimization. Further experiments and calculations will be conducted in the future and it is necessary to determine the number of HP, the loading capacity of the PCM, and the optimum melting point of the PCM.

\section{Acknowledgements}

The authors would like to thank Mr. Seiichiro Ishii in Uzushio Electric Co., Ltd. for advice about the experimental equipments. We also thank Mr. Konosuke Kitamura in ANSYS Japan K. K. for advice about detailed usage of ANSYS Fluent.

\section{References}

Al-Hallaj, S. and Selman, J. R., A novel thermal management system for electric vehicle batteries using phase change material, Transactions of the electrochemical society, 147, 9 (2000), 3231-3236.

Fan, L., Khodadadi, J. M. and Pesaran, A. A., A parametric study on thermal management of an air-cooled lithium-ion battery module for plug-in hybrid electric vehicles, Journal of Power Sources, 238 (2013), 301-312.

Feng, X., Ouyang, M., Liu, L., Xia, Y. and He, X., Thermal runaway mechanism of lithium ion battery for electric vehicles: A review, Energy Storage Materials, (2017), http://dx.doi.org/10.1016/j.ensm.2017.05.013

Hammami, A., Raymond, N. and Armand, M., Lithium-ion batteries: Runaway risk of forming toxic compounds, Nature Vol.424 (2003) pp.635-636.

Hamut, H. S., Dincer, I. and Naterer, G.F., Exergy analysis of a TMS (thermal management system) for range-extended EVs (electric vehicles), Energy, 46 (2017), 117-125.

International Energy Agency, Global EV Outlook 2017 Two million and counting, (2017), p5-6.

Javani, N., Dincer, I., Naterer, G. F. and Yilbas, B. S., Heat transfer and thermal management with PCMs in a Li-ion battery cell for electric vehicles, International Journal of Heat and Mass Transfer, 72 (2014), 690-703.

Khateeb, S. A., Amiruddin, S., Farid, M., Selman, J. R. and Al-Hallaj, S., Thermal management of Li-ion battery with pahase change material for electric scooters: experimental validation, Journal of Power Sources, 142 (2005), 345 353. 
Lisbona, D. and Snee, T., A review of hazards associated with primary lithium and lithium-ion batteries, Process Safety and Environmental Protection, 89 (2011), 434-442.

Mohammadian, S. K. and Zhang, Y., Thermal management optimization of an air-cooled Li-ion battery module using pin-fin heat sinks for hybrid electric vehicles, Journal of Power Sources, 273 (2015), 431-439.

Pesaran, A., Santhanagopalan, S. and Kim, G.-H., Addressing the impact of temperature extremes on large format Li-ion batteries for vehicle applications, in: 30th International Battery Seminar, Ft. Lauderdale, Florida, (2013).

Poizot, P. and Dolhem, F., Clean energy new deal for a sustainable world: from non-CO2 generating energy sources to greener electrochemical storage devices, Energy Environ. Sci., (2011) 4, 2003-2019.

Qian, Z., Li, Y. and Rao, Z., Thermal performance of lithium-ion battery thermal management system by using minichannel cooling, Energy Conversion and Management, 126 (2016), 622-631.

Ramadass, P., Haran, B., White, R. and Popov, B.N., Capacity fade of Sony 18650 cells cycled at elevated temperatures Part 1. Cycling performance, Journal of Power Sources 112 (2002a) 606-613.

Ramadass, P., Haran, B., White, R. and Popov, B.N., Capacity fade of Sony 18650 cells cycled at elevated temperatures Part 2. Capacity fade analysis, Journal of Power Sources 112 (2002b) 614-620.

Rao, Z., Wang, Q. and Huang, C., Investigation of the thermal performance of phase change material/mini-channel coupled battery thermal management system, Applied Energy, 164 (2016), 659-669.

Saito, Y., Kanari, K. and Takano, K., Thermal studies of a lithium-ion battery, Journal of Power Sources, 68 (1997), 451454.

Scrosati, B. and Garche J., Lithium batteries: Status, Prospects and future, Journal of Power Sources, 195 (2010), 2419 2430.

Tie, S. F. and Tan, C. W., A review of energy sources and energy management system in electric vehicles, Renewable and Sustainable Energy Reviews, 20 (2013), 82-102.

Wang, Q., Ping, P., Zhao, X., Chu, G., Sun, J. and Chen, C., Thermal runaway caused fire and explosion of lithium ion battery, Journal of Power Sources, 208 (2012), 210-224.

Wang, Q., Jiang, B., Li, B. and Yan, Y., A critical review of thermal management models and solutions of lithium-ion batteries for the development of pure electric vehicles, Renewable and Sustainable Energy Reviews, 64 (2016), 106128.

Xu, J., Lan, C., Qiao, Y. and Ma, Y., Prevent thermal runaway of lithium-ion batteries with minichannel cooling, Applied Thermal Engineering, 110 (2017), 883-890.

Yamada, T., Koshiyama, T., Yoshikawa, M., Yamada, T. and Ono, N., Analysis of a lithium-ion battery cooling system for electric vehicles using a phase-change material and heat pipes, Journal of Thermal Science and Technology, Vol. 12, No.1, (2017), pp. 1-15, [DOI: 10.1299/jtst.2017jtst0011].

Yuksel, T., Lister, S., Viswanathan, V. and Michalek, J. J., Plug-in hybrid electric vehicle $\mathrm{LiFePO}_{4}$ battery life implications of thermal management, driving conditions, and regional climate, Journal of Power Sources, 338 (2017), 49-64.

Zhang, Y. P., Yu, X. L., Feng, Q. K. and Zhang, R. T., Thermal performance study of integrated cold plate with power module, Applied Thermal Engineering, 29 (2009), 3568-3573. 